\title{
LA MOVILIZACIÓN DE COMPETENCIAS Y EL DESARROLLO COGNITIVO UNIVERSAL-BILATERAL DEL APRENDIZAJE EN LA ENSEÑANZA DE LAS CIENCIAS
}

\author{
Everton Bedin \\ bedin.everton@gmail.com \\ https://orcid.org/0000-0002-5636-0908 \\ Universidade Federal do Paraná, Brasil \\ José Claudio Del Pino \\ delpinojc@yahoo.com.br \\ https://orcid.org/0000-0002-8321-9774 \\ Universidade do Vale do Taquari, Brasil
}

Recibido: 02/04/2020 Aceptado: 25/05/2020

\begin{abstract}
Resumen
Este artículo tiene como objetivos, presentar una metodología de enseñanza llamada DICUMBA (Desarrollo Cognitivo Universal-Bilateral del Aprendizaje), y reflexionar sobre cómo el aprendizaje a través de la investigación centrada en el estudiante (Aprender pela Pesquisa Centrada no Aluno, APCA), cuando se desarrolla a partir del interés y la inserción activa de éste en el aula, permite la movilización de habilidades para la formación crítica y ética. En esta investigación cualitativa que se desarrolló en cinco pasos, participaron 3 maestros y 85 estudiantes. Para la recolección de información, además de la observación participante, se utilizó un cuestionario de validación. Al final, después de un análisis detallado de las respuestas al cuestionario dadas por los estudiantes y docentes en el cuestionario, así como de la interpretación empírica y transversal de la investigación desarrollada por los estudiantes a la luz del APCA, queda claro que el Desarrollo Cognitivo Universal-Bilateral del Aprendizaje (DICUMBA) en la educación científica se configura como una acción que motiva y estimula a los estudiantes a enseñar, haciéndolos participar en múltiples acciones que requieren la movilización de habilidades para organizar diferentes niveles del dominio cognitivo.
\end{abstract}

Palabras clave: Aprendizaje por investigación. DICUMBA. Movilización de habilidades.

\section{MOBILIZAÇÃO DE COMPETÊNCIAS E O DESENVOLVIMENTO COGNITIVO UNIVERSALL-BILATERAL DA APRENDIZAGEM NO ENSINO DE CIÊNCIAS}

\begin{abstract}
Resumo
Este artigo tem como objetivos apresentar um método de aprendizagem chamado DICUMBA (Desenvolvimento Cognitivo Universal-Bilateral da Aprendizagem) e refletir sobre como Aprender pela Pesquisa Centrada no Aluno (APCA), quando se desenvolve a partir dos interesses e da sua inserção ativa na sala de aula, permite a mobilização de habilidades para a própria formação crítica e ética. Nesta pesquisa qualitativa, realizada em cinco etapas, participaram 3 professores e 85 alunos. Para a coleta de informações, além da observação participante, foi utilizado um questionário de validação. Por fim, após uma análise detalhada das respostas dadas pelos alunos e professores ao questionário, bem como a interpretação empírica e transversal da pesquisa realizada pelos alunos à luz da APCA, fica claro que o Desenvolvimento Cognitivo Universal-Bilateral da Aprendizagem (DICUMBA) no ensino de
\end{abstract}


ciências se configura como uma ação que motiva e estimula os alunos a aprender, participando de múltiplas ações que exigem a mobilização de habilidades para organizar diferentes níveis de domínio cognitivo.

Palavras-chave: Aprendizagem em pesquisa. DICUMBA Mobilização de habilidades.

\title{
MOBILIZATION OF COMPETENCES AND THE DEVELOPMENT COGNITIVE UNIVERSAL-BILATERAL LEARNING IN SCIENCE TEACHING
}

\begin{abstract}
This article aims to present a learning method called DICUMBA (Universal-Bilateral Cognitive Development of Learning) and reflect on how to Learn through Student-Centered Research (APCA), when it develops from the interests and its active insertion in the classroom, allows the mobilization of skills for critical and ethical training. In this qualitative research, carried out in five stages, 3 teachers and 85 students participated. For the collection of information, in addition to participant observation, a validation questionnaire was used. Finally, after a detailed analysis of the answers given by the students and teachers to the questionnaire, as well as the empirical and transversal interpretation of the research carried out by the students in the light of the APCA, it is clear that the Universal-Bilateral Cognitive Development of Learning (DICUMBA) in teaching of sciences is configured as an action that motivates and encourages students to learn, participating in multiple actions that require the mobilization of skills to organize different levels of cognitive domain.
\end{abstract}

Keywords: Research learning. DICUMBA Mobilization of skills.

\section{Introdução}

Historicamente, o ensino das Ciências da Natureza tem sofrido com a forma em que vem sendo desenvolvido, principalmente, na Educação Básica. Afinal, por se constituir em uma das principais áreas para a formação do aluno, os componentes curriculares química, física e biologia, de uma forma geral e a partir da prática pedagógica, têm sido, predominantemente, desenvolvidos e interpretados apenas a partir da ação de memorizar os conteúdos, os símbolos, as fórmulas e os códigos e linguagens específicas, ficando a cargo dos professores a transmissão de informações, muitas vezes, irrelevantes, não significativas e descontextualizadas à vivência do aluno (Bedin, 2019).

Nesta perspectiva, tem-se a falta de interesse, a baixa curiosidade e a ilusória perspectiva em aprender pelo aluno da Educação Básica não simplesmente em relação aos conteúdos específicos destes componentes curriculares, mas aqueles em que deles fazem parte. De outra forma, o saber científico relacionado as Ciências da Natureza não têm provocado no aluno o desejo e a vontade de aprender, despertando nos professores a noção da necessidade de refletir 
e de agir sobre os próprios métodos utilizados na transposição dos conteúdos e dos conceitos científicos durante os ambientes de aprendizagem.

Nass e Fischer (2016, p. 23), em especial à química, afirmam que a forma em que "vem sendo abordada nas escolas privilegia a memorização de fórmulas e conceitos, além de que há professores que só trabalham com o quadro e giz, [...] sem estabelecer uma relação com algo concreto para o aluno, do seu cotidiano". Em consequência desta ação, validando a atuação do professor como um transmissor de informação científica sem vínculo contextual com o aluno, com vistas a aprovação em provas e em exames, percebe-se a minimização desta área do conhecimento em múltiplas esferas sociais, políticas e culturais.

Neste desenho, entende-se que ao final do Ensino Médio o aluno não tem condições de mobilizar competências e de acionar habilidades para resolver uma situação-problema contextualizada, situações diárias e, até mesmo, problemas relacionados com a própria vivência. Isto é, por não ter um ensino de qualidade e contextualizado durante os três últimos anos de sua formação na Educação Básica, de acordo com Nass e Fischer (2016), a grande maioria dos alunos não tem condição de exercer um papel científico na sociedade, já que está saindo da instituição de ensino sem conhecimento mínimo necessário para atuar de forma científica.

Diante do exposto, acredita-se ser necessário, urgentemente na Educação Básica, em especial no ensino das Ciências da Natureza, uma mudança significativa em relação a metodologia dos professores e a forma e a maneira como estes desenvolvem seus ambientes de aprendizagem à luz da ciência, a fim de que se possa instigar o aluno cognitivamente para além de entender a química, a física e a biologia como carros chefe do seu desenvolvimento social, cultural e econômico, compreendê-las como ciências para além de explicar fenômenos naturais e artificiais que fazem parte do seu contexto.

De outra forma, acredita-se que a inserção de novas metodologias de ensino, ou o aperfeiçoamento da prática pedagógica à luz de ações inovadoras e contemporâneas, as quais possam contribuir para o desenvolvimento de habilidades e a mobilização de competências necessárias para preparar o aluno para a vida social e científica, constituindo-o através dos conhecimentos específicos da área das Ciências da Natureza, seja de extrema urgência para permitir ao aluno a possibilidade de construir seus próprios conceitos e descobrir uma forma de aprender dinamicamente (Filho et al., 2011). 
Assim, este artigo tem por objetivo, além de apresentar uma metodologia de ensino denominada DICUMBA - Desenvolvimento Cognitivo Universal-Bilateral da Aprendizagem , refletir sobre como o Aprender pela Pesquisa Centrada no Aluno (APCA), ação derivada da DICUMBA, quando desenvolvida a partir do desejo, da curiosidade e da inserção ativa e argumentativa do aluno em sala, lhe possibilita a mobilização de competências para a formação cidadã, crítica e ética, bem como o aperfeiçoamento pedagógico e curricular dos professores participantes.

\section{A Metodologia DICUMBA e a Mobilização de Competências}

A metodologia DICUMBA é uma proposta de ensino desenvolvida pelos autores a partir de consecutivas pesquisas, reflexões e discussões sobre o modelo egocêntrico e hegemônico de desenvolver os processos de ensino e aprendizagem à luz do ensino das ciências na Educação Básica, tendo como motivação e princípio de emersão as angústias, as incertezas e os sentimentos envolvidos em pesquisas lato sensu (especialização) e stricto sensu (mestrado e doutorado) realizadas por um dos autores. Basicamente, a proposta da metodologia é desenvolver o ensino de ciências (em especial o ensino de química) a partir daquilo que o aluno tem interesse e desejo em Aprender pela Pesquisa, pois, assim, acredita-se que o mesmo será capaz de constituir habilidades e de mobilizar competências necessárias à ressignificação de saberes e a inclusão de novas sapiências; a metodologia proporciona ao professor diferentes formas de ressignificar o saber prévio-contextual do aluno, despertando no mesmo a motivação pela aquisição dos saberes específicos dos componentes curriculares que compõem uma área (Bedin \& Del Pino, 2018a, b).

De outra forma, a DICUMBA proporciona ao aluno o papel de sujeito adjunto no desenvolvimento do ensino de Ciências da Natureza, pois os conceitos e os conteúdos dos componentes curriculares são inseridos após o aluno selecionar um tema norteador para o desenvolvimento de uma pesquisa que transita entre o social e o científico. Ou seja, o aluno decide sobre o que quer estudar e, então, os professores realizam conexões com o conteúdo de química, física e biologia, não necessariamente para aquela determinada série do Ensino Médio onde o aluno se encontra, mas de uma forma abrangente, complexa e profunda, a fim de que o estudante consiga, no desenvolver de suas atividades, Aprender pela Pesquisa, retomar o conteúdo e significar o conhecimento científico ao seu contexto, como explícito no pentagrama abaixo (Figura 1). 
Figura 1. Pentagrama das ações desenvolvidas na metodologia DICUMBA

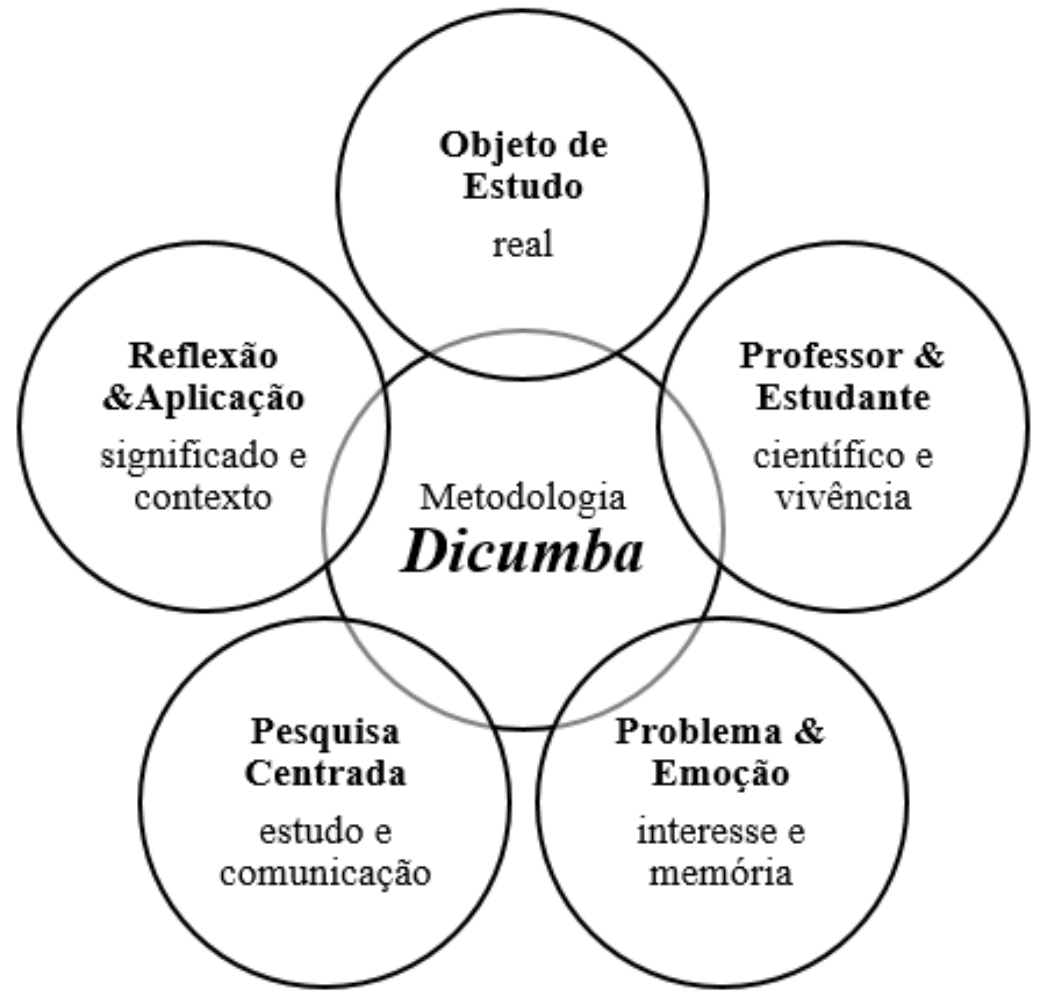

Fonte: Bedin \& Del Pino (2019a, p. 17).

Esta metodologia tira o papel central (no sentido de detentor do conhecimento) do professor na Educação Básica, fazendo com que este se torne um facilitador do processo de construção de conhecimentos do aluno a partir do Aprender pela Pesquisa. O professor deixa de ser o detentor do saber, o transmissor de informações prontas e acabadas, e faz com que o aluno, enquanto sujeito significativo em construção, passe a construir e a internalizar um perfil científico a partir da pesquisa realizada. Esta ação requer a constituição de habilidades e a mobilização de múltiplas competências por parte do aluno; é um processo contínuo de construção e reconstrução, fazendo com que este sujeito se aprofunde naquilo que quer entender e acabe assimilando e distinguindo os conteúdos gerais das ciências, bem como se apropriando da argumentação crítica e do raciocino lógico reflexivo (Bedin \& Del Pino, 2019b).

Nesta perspectiva, a metodologia DICUMBA proporciona a interlocução de saberes científicos, àqueles advindos dos saberes curricular e profissional dos professores, com os saberes sociais, àqueles derivados da relação com a sociedade e com o mundo do aluno, fazendo com que a aprendizagem ocorra de forma universal-bilateral, como demonstrado na Figura 2. Nesta relação exigente entre a mobilização e a interlocução cognitiva de saberes científicos e 
sociais, como ressalva Masetto (2013, p. 151), a competência docente passa a ser vista como "a atitude, o comportamento do professor que se coloca como um facilitador, incentivador ou motivador da aprendizagem, que se apresenta com a disposição de ser uma ponte entre o aprendiz e sua aprendizagem".

Figura 2. A ressignificação dos saberes a partir da metodologia DICUMBA

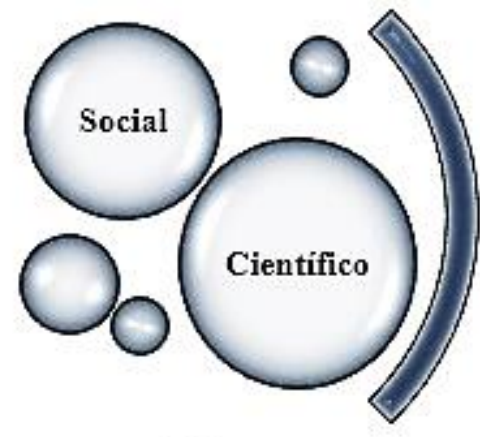

Saberes descontextualizados

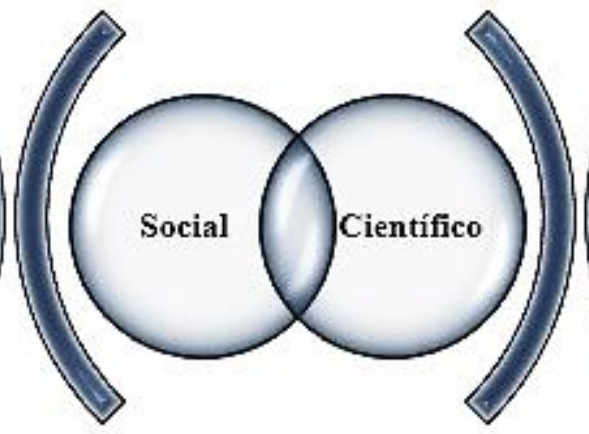

Interlocução

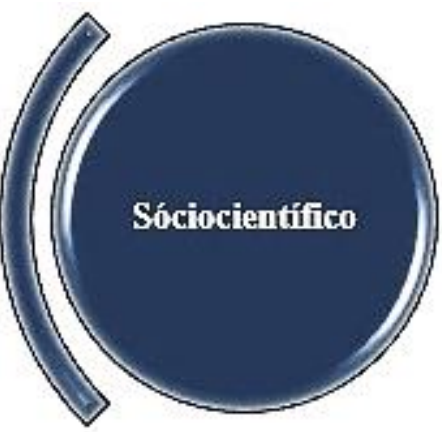

Saber ressignificado

Fonte: Autores, 2020.

A partir da interpretação do conteúdo da Figura 2, pode-se perceber que a proposta da metodologia DICUMBA, derivando-se na ação do Aprender pela Pesquisa Centrada no Aluno (APCA), implica na interligação efetiva entre os saberes do aluno e os saberes dos professores, sujeitos envolvidos nos processos de ensino e aprendizagem, de forma ativa, conjunta e colaborativa, contemplando um objeto de estudo real que deriva do interesse do aluno para a constituição de um único saber, aquele ressignificado cientificamente à realidade do sujeito.

Nesta perspectiva, percebe-se que, a partir da aplicação da metodologia DICUMBA, o aluno começa a mobilizar suas competências para entender o conteúdo científico relacionado ao seu interesse. Esta ação individual do sujeito exige, além de uma organização de ideias e otimização de espaço/tempo, segurança significativa em relação a criticidade e a autonomia para a pesquisa; logo, tem-se a formação de uma argumentação e de uma consciência crítica para expressar conhecimento específico na (re)construção de saberes e na produção de novos conhecimentos, os quais ocorrem a partir da fusão entre o saber social e o saber científico.

Contudo, ressalva-se que a ideia de pesquisar a partir do desejo e da curiosidade do aluno para desenvolver os conceitos e os conteúdos dos componentes curriculares associados a área das Ciências da Natureza não é reajustar uma informação ao conjunto ou ao contexto do aluno, 
pois, como afirma Ens (2006, p. 1), “o conhecimento, para o seu desenvolvimento, precisa usar de forma ampla e irrestrita a curiosidade intelectual do ser humano, ampliando o espírito de investigação”. Ens (2006) ainda complementa que:

[...] no processo de pesquisar surge a indagação sobre como unir experiência pessoal, atitude científica, atitude crítica, a própria crítica, a atitude empírica, pois a razão, a experiência, a crítica, a crítica da crítica, a práxis, a comunicação, a reflexão são ações necessárias umas às outras, tanto num processo de pesquisa, como num ato dialógico, em que o conhecimento emerge de um problema voltado ao objeto de estudo durante a investigação. (Ens, 2006, p. 1)

A reflexão que surge a partir das colocações de Ens (2006), e do entendimento da funcionalidade da metodologia DICUMBA, é que os professores precisam ter um corpus teórico de suas disciplinas, significativamente amplo e conciso, para analisar, encaixar, orientar e ressignificar o saber social do aluno à luz dos conteúdos e dos conceitos da ciência. Em outras palavras, a metodologia DICUMBA não proporciona a mobilização de competências e a constituição de novas sapiências somente ao aluno, mas intensifica a forma de os professores conseguirem entender e estudar a sua área do saber, pois a pesquisa, por ser centrada no aluno e desenvolvida a partir do interesse e da curiosidade do mesmo, requer que os professores, apesar de possuírem os conteúdos mínimos pré-estabelecidos para uma determinada série do Ensino Médio, consigam trabalhar de forma inter e intradisciplinar, agregando conhecimentos e saberes muitas vezes esquecidos e/ou não estudados.

É neste sentido que a metodologia DICUMBA, realçada no APCA, deve ser entendida como uma tríade de princípios: 1. Princípio pedagógico-científico; 2. Princípio formativoarticulador; e 3. Princípio educativo-crítico, na formação do sujeito da Educação Básica e da formação continuada dos professores de Ciências da Natureza. Assim, no princípio pedagógicocientífico, a metodologia passa a ser compreendida como uma forma de ressignificar os saberes científicos do professor ao contexto sociocultural do aluno, sendo "um elemento-chave para a formação emancipatória" (Cunha, 2003, p. 3) dos sujeitos. Como princípio formativoarticulado, a metodologia passa a ser considerada um mecanismo de formação de identidade do sujeito e de argumentação crítica, pois busca constituir-se a partir da própria autonomia de escolha. Além do mais, como um princípio educativo-crítico, a metodologia passa a ser 
interpretada como uma forma de maximizar os processos de ensino e aprendizagem à qualificação do interesse, da dedicação e do desejo em aprender pelo aluno.

Nesta esfera, a metodologia que aqui se apresenta é significativamente potente para mudar, ou ao menos tentar mudar, o cenário do ensino de Ciências da Natureza nas escolas públicas de hoje, pois a ação de pesquisar tem/terá um caráter investigativo quando o sujeito conseguir, no decorrer do próprio processo de formação, realizar "uma triangulação entre os princípios científico, formativo e educativo da pesquisa" (Ens, 2006, p. 1). Nesta triangulação específica do APCA, pode-se perceber que o professor, além de se encontrar ativamente em processo de formação, aperfeiçoando-se constantemente a partir da troca, do estudo e da autorreflexão, poderá alimentar e conduzir os alunos ao processo de aprender a aprender cientificamente.

A triangulação representada na Figura 3 é uma forma de demonstrar como a ação entre os professores e o aluno, mediada pela metodologia DICUMBA, favorece a mobilização de competências e de atitudes no aluno, uma vez que este precisa, a partir do saber sociocultural, internalizar os saberes educativos, formativos e científicos, reconstruindo-os à luz do seu contexto. Ademais, Bedin (2017) reflete que quando se proporciona uma atividade na Educação Básica que demanda uma ação conjunta entre o professor e o aluno para ser desenvolvida, esta atividade também propicia um avanço significativo na relação professor-aluno.

Figura 3: Saberes relacionados e ressignificados a partir da mobilização de competências.

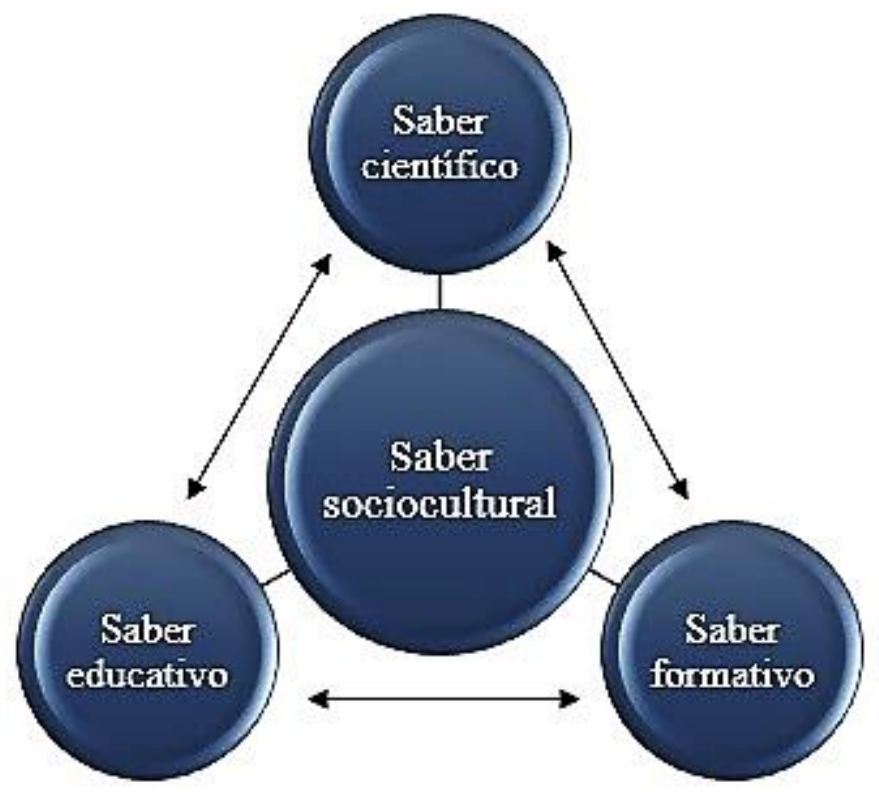

Fonte: Autores, 2020. 
A mobilização de competências é uma ação fundamental para a aprendizagem do aluno, pois é só a partir dela que é possível diagnosticar efetivamente a aprendizagem adquirida. Em outras palavras, fazer com que o aluno mobilize competências para conseguir chegar a um resultado desejado, a partir da ação docente e da pesquisa centrada em seu interesse, é um instrumento significativo para diagnosticar lacunas na aprendizagem, facilitar o planejamento de ações pedagógicas para maximizar a ensinagem e, em consequência, melhorar o desempenho dos alunos frente a maneira de aprender a aprender.

Mobilização de competência diz respeito a ideia de o aluno conseguir realizar uma atividade, em um determinado contexto e frente a diferentes situações, de forma satisfatória e eficaz (Zabala \& Arnau, 2010); é uma forma interconectada de mobilizar caráteres, agilidades e saberes ao mesmo tempo. No Brasil, por meio da Lei de Diretrizes e Bases (LDB), $n^{\circ}$ 9.394/1996, o conceito de competências foi introduzido ao assegurar que o currículo na Educação Básica, em especial no Ensino Médio, deveria guiar o desenvolvimento de competências para cidadania. No parecer CNE/CEB 16/995, que trata das Diretrizes Curriculares para a Educação Profissional, o conceito de competências é entendido como "[...] a capacidade de articular, mobilizar e colocar em ação valores, conhecimentos e habilidades necessários para o desenvolvimento eficiente e eficaz de atividades requeridas pela natureza do trabalho" (Brasil, 1999, p. 2). No ano de 2001, o parecer CNE/CP 9/20016, mesmo referente a formação de professores, traz o conceito afirmando que "não basta a um profissional ter conhecimentos sobre seu trabalho. É fundamental que saiba mobilizar esses conhecimentos, transformando-os em ação" (Brasil, 2001, p. 29).

Não obstante, o Exame Nacional do Ensino Médio (ENEM), realizado anualmente pelo Ministério da Educação desde o ano de 1998, é aplicado como fim de avaliação do desempenho dos estudantes a partir de áreas do conhecimento e de cinco competências. 1 - Dominar linguagens; 2 - Compreender fenômenos; 3 - Enfrentar situações-problema; 4 - Construir argumentações; e 5 - Elaborar propostas. Nesta mescla de conceitos e direções sobre o que são as competências e como mobiliza-las, a única certeza que se encontrar é de que estas são, a partir de um corpus teórico, uma construção específica, individual e singular de cada sujeito, sendo moldada a partir da realidade, da situação e da vivência de cada indivíduo; uma competência não tem como ser vista, apenas pode-se analisar os seus efeitos (Rey, 2005). 
Entre os diversos conceitos estabelecidos na literatura sobre a ideia central de competência, neste artigo, adotou-se o significado apresentado por Cruz (2001), pois este autor define a competência como um conceito que acolhe conhecimentos, atitudes e perspectivas, envolvendo o espaço do self (saber-ser), o espaço cognitivo (saber formalizado) e o espaço comportamental (saber-fazer). Em sintonia, Alves (2005) ajuíza o conceito de competência como a forma em que o sujeito estrutura, articula e relaciona os diferentes saberes, atitudes e valores; é uma ação cognitiva em que o sujeito a aprimora e maximiza na medida em que ressignifica os saberes universais com o auxílio dos professores de forma bilateral, isto é, a metodologia DICUMBA.

Portanto, em conformidade com as ideias de Cruz (2001) e a própria natureza da mobilização de competências necessária ao Ensino Médio, adotou-se, como mecanismo de avaliação, as competências estabelecidas na Base Nacional Comum Curricular (BNCC) (Brasil, 2018), pois neste documento se esclarece a continuação das competências adquiridas e mobilizadas no Ensino Fundamental. Ressalta-se que não se fará jus no artigo sobre as certezas e incertezas, construções e desconstruções, acertos e erros da BNCC, muito menos quaisquer comentários que possam desvincular o real objetivo deste trabalho; logo, adotou-se as competências da BNCC apenas como critérios de logística e organização de dados por apresentar-se em área de conhecimento.

\section{Metodologia da Pesquisa}

O trabalho, o qual foi tecido como ponte para a coleta dos dados da pesquisa, foi proposto pelos professores da área das Ciências da Natureza, o qual derivou do intuito de fazer com que o estudante entendesse alguns conteúdos e conceitos das diferentes disciplinas que compõem esta área dentro do seu contexto, significando algo que, realmente, fosse/é interessante e importante para ele. Ao tocante, os três professores da área das Ciências da Natureza (química, física e biologia), a fim de mobilizarem múltiplas competências e constituírem diferentes habilidades nos alunos, desenvolveram a atividade à luz da metodologia DICUMBA. Para tal ação, os professores seguiram os seguintes passos:

$1^{\mathrm{o}}$ - problematizaram o ensino de ciências, fazendo com que os estudantes refletissem sobre os conteúdos e conceitos curriculares presentes no contexto de cada um; $2^{\circ}$ - instigaram o aluno a pensar qualquer tema/assunto relacionado ao seu contexto sociocultural, algo que realmente despertasse o interesse e a curiosidade em estudar, enfatizando situações-problemas; 
$3^{\text {o }}$ - solicitaram ao aluno que justificasse o interesse pelo tema e, aos poucos, conectavam, em forma de dúvidas e problemas, um conteúdo/conceito de cada disciplina dentro do tema apresentado pelo aluno; $4^{\circ}$ - estimularam o aluno a fazer uma pesquisa centrada nos conteúdos e nos conceitos problematizados por cada professor relacionados à temática; e $5^{\circ}$ - propuseram ao aluno apresentar/socializar seu trabalho a turma e, em meio a esta ação, complementaram de forma explicativa e científica os conteúdos que foram determinados para a pesquisa.

Após essa ação, um dos professores da área dialogou com os alunos sobre o que são as competências e as habilidades que, supostamente, eles haviam mobilizado e desenvolvido ao realizar o trabalho, refletindo sobre a importância de o aluno pesquisar e aprender por meio da pesquisa como princípio pedagógico, já que esta prática o faz ser mais autônomo, ativo e crítico nos processos de ensino e aprendizagem. Posteriormente, este mesmo professor aplicou um questionário aos alunos e aos professores da área das Ciências da Natureza. No questionário, apresentou-se as três competências para a área de Ciências da Natureza presentes na BNCC; os estudantes, assim como os professores, deveriam assinalar com um " $\mathrm{x}$ " as competências mobilizadas pelos alunos no desenvolvimento do trabalho.

Neste desenho, tem-se que o questionário, na visão de Gil (1999, p. 128), é uma “técnica de investigação composta por um número mais ou menos elevado de questões apresentadas por escrito às pessoas, tendo por objetivo o conhecimento de opiniões, crenças, sentimentos, interesses, expectativas, situações vivenciadas, etc”. O questionário, para Parasuraman (1991), é um contíguo de questões elencadas para garantir o alcance de uma pesquisa; logo, um instrumento com questões cientificamente elaboradas e criteriosamente ordenadas devendo ser respondido na presença do entrevistador (Marconi \& Lakatos, 1999).

Quanto as vantagens da utilização do questionário, autores como Marconi e Lakatos (1999), bem como Hair e seus colaboradores (2004), afirmam que encontram-se a economia de tempo, o grande número de dados, a obtenção de respostas rápidas, diretas e precisas, o anonimato do respondente, a não influência do pesquisador e a não necessidade de sua presença a campo e, dentre outras, o alcance de um grupo específico e a escolha do momento ideal para o respondente responder.

Assim, esta pesquisa apresenta um caráter descritivo de cunho qualitativo; a pesquisa é de cunho descritivo-qualitativo porque, além do questionário, todo o desenvolvimento do trabalho pelos alunos foi supervisionado pelos três professores da área, o que significa que as 
reflexões e os argumentos sobre a análise deste questionário estão abluídos as considerações destes professores, bem como descritos de forma qualitativa; logo, buscou-se descrever as especificidades e as características de uma determinada população (Gil, 1999).

Ao término, ajuíza-se que o trabalho foi desenvolvido com, aproximadamente, 85 alunos de três terceiros anos do Ensino Médio, mas a aplicação do questionário e a validação das competências mobilizadas por estes foram extensivas a uma parcela desta amostra, pois buscouse, no viés do estudo de caso, o aprofundamento daquela realidade específica, a fim de lograr satisfação legível sobre as explicações e as interpretações do grupo (Gil, 2008). Portanto, as respostas presentes neste trabalho são extensíveis a 27 alunos do terceiro ano do Ensino Médio de uma escola pública do município de São Leopoldo, município metropolitano de Porto Alegre, capital do Estado do Rio Grande do Sul/Brasil.

\section{Resultados e Discussão}

A análise e a interpretação dos dados se pautaram em uma abordagem qualitativa. $\mathrm{Ou}$ seja, apesar de abaixo aparecerem alguns dados percentuais sobre a mobilização de competências do universo da pesquisa, acredita-se que estes não são o suficiente para determinar a pesquisa em um viés quantitativo. Afinal, como supracitado, foi por meio da prática de observação participante do professor, da descrição e da crítica analítica, que tornou-se possível realizar uma avaliação do comportamento dos sujeitos durante o desenvolvimento do trabalho e mensurar os dados à luz da metodologia DICUMBA.

Neste sentido, alguns passos foram considerados importantes e sequenciais durante a explicação e o desenvolvimento da atividade aos alunos, tais como: i) motivação em realizar a atividade e selecionar um tema de interesse e de impacto sociocultural; ii) dedicação para pesquisar e resolver as incógnitas explanadas pelos professores; iii) argumentação crítica e reflexiva durante a socialização das pesquisas para os demais colegas, enfatizando os comentários direcionados aos conteúdos.

Assim, torna-se fundamental, antes de apresentar o percentual de competências mobilizadas pelos alunos na perspectiva destes e dos professores, algumas considerações de um dos professores da área, o qual norteou todo o desenvolvimento da atividade. De acordo com o professor, o principal impacto da atividade desenvolvida à luz da DICUMBA foi a relação das áreas na constituição de um único saber aos alunos, mostrando-lhes que a ciência é um saber 
abrangente que conecta e se bifurca em diversos vieses; não é uma verdade ou um dogma, mas algo construído historicamente a partir de estudos, fenômenos e experiências.

Além disso, segundo o professor, a metodologia DICUMBA proporcionou uma troca de saberes dentro da sala de aula de forma significativa, pois os alunos puderam no viés de cada componente curricular, dentro de suas especificidades e temas de pesquisa, ressignificar conceitos, retomar conhecimentos, intensificar os conteúdos, maximizar os saberes e, para além do científico, mobilizar competências, desenvolver interesse inter e intrapessoal e social pelo tema, compartilhar opiniões, ideias e concepções em relação ao próprio tema e ao do colega, bem como argumentar cientificamente sobre algo.

Desta forma, percebe-se que a atividade do APCA se constitui em uma relevante estratégia de ensino, uma vez que contribui satisfatoriamente para a aprendizagem num ambiente cooperativo e dialógico, motivando os estudantes a entenderem ciências a partir de um tema de interesse e de curiosidade própria de estudo. Logo, tem-se a formação de um sujeito ativo, autônomo e crítico durante o processo de desenvolvimento da Alfabetização Científica e da argumentação crítica na Educação Básica, pois a atividade, além de concentrar-se no científico, foi significativamente importante para fazer do aluno um sujeito adjunto no processo de ensinagem, desenvolvendo um espírito crítico de pesquisador. Afinal, de acordo com Rangel, Bedin e Del Pino (2019), “a DICUMBA visa desenvolver autonomia, argumentação crítica e senso de expressão no aluno, permitindo-o se perceber como membro da construção de sua aprendizagem a partir da constituição de saberes científicos via interesses pessoal e social".

Neste viés, relacionando-se as colocações do professor, o qual participou ativamente do processo, percebe-se que a funcionalidade da atividade ultrapassou o desejo de fazer com que o estudante estudasse a partir do próprio interesse, motivando-se e dedicando-se por inteiro neste processo de mobilizar competências para compreender novos e restaurar velhos significados. Afinal, "a necessidade incide na motivação e quanto mais motivado o aluno estiver mais aproveitará os recursos de que dispõe para aprender, mais estratégias utilizará para conseguir seu objetivo e quantas mais utilizar, mais rápido e melhor aprenderá” (Benítez, 2010, p. 3).

Ademais, para intensificar detalhadamente as competências mobilizadas pelos sujeitos no desenvolvimento da atividade, apresentando as contribuições da metodologia DICUMBA neste processo, como supracitado, dados emergentes de um questionário aplicado aos alunos e aos professores possibilitou a verificação de alguns indicadores. Portanto, após o 
desenvolvimento de toda a atividade, os alunos, assim como os professores, pontuaram as competências que foram mobilizadas à aplicação e a eficácia da atividade desenvolvida, buscando-se subsídios de competências a partir daquelas explanadas na BNCC, conforme Quadro 1.

Quadro 1: Competências Gerais Presentes na Base Nacional Comum Curricular para a Área das Ciências da Natureza na Educação Básica no Ensino Médio.

\section{Competências Gerais}

C1 Analisar fenômenos naturais e processos tecnológicos, com base nas relações entre matéria e energia, para propor ações individuais e coletivas que aperfeiçoem processos produtivos, minimizem impactos socioambientais e melhorem as condições de vida em âmbito local, regional e/ou global.

Construir e utilizar interpretações sobre a dinâmica da Vida, da Terra e do Cosmos

C2 para elaborar argumentos, realizar previsões sobre o funcionamento e a evolução dos seres vivos e do Universo, e fundamentar decisões éticas e responsáveis.

Analisar situações-problema e avaliar aplicações do conhecimento científico e tecnológico e suas implicações no mundo, utilizando procedimentos e linguagens

C3 próprios das Ciências da Natureza, para propor soluções que considerem demandas locais, regionais e/ou globais, e comunicar suas descobertas e conclusões a públicos variados, em diversos contextos e por meio de diferentes mídias e tecnologias digitais de informação e comunicação (TDIC).

Fonte: Brasil (2018, p. 534) - grifo nosso.

Portanto, após a realização do trabalho, buscou-se interpretar e validar as ações da metodologia quanto a mobilização de competências dos alunos com vistas ao Quadro 1, traçando-se um perfil significativo da ação da metodologia na constituição/mobilização destas competências; confia-se que a metodologia DICUMBA, por proporcionar o desenvolvimento dos processos de ensino e aprendizagem a partir do interesse e das perspectivas de estudo do aluno, seja uma forma significativa para desenvolver uma nova forma de aprender e ensinar na Educação Básica brasileira.

Com base nas colocações dos sujeitos no questionário, tanto dos professores quanto dos 27 alunos, elaborou-se a Tabela 1. Nela é possível averiguar a quantidade em porcentagem de alunos que mobilizou cada competência, na visão destes e dos professores. 
Tabela 1: Percentual e Competências Mobilizadas Na Percepção De Alunos E Professores.

\begin{tabular}{c|c|c}
\hline Competências & Alunos & Professores \\
\hline C1 & $70,3 \%$ & $88,9 \%$ \\
\hline C2 & $85,2 \%$ & $92,6 \%$ \\
\hline C3 & $92,6 \%$ & $100 \%$ \\
\hline
\end{tabular}

Fonte: Dados da pesquisa, 2019.

Buscando intensificar os dados da tabela acima, apresenta-se no Quadro 2, cinco pesquisas realizadas pelos alunos, dando-se ênfase aos temas de pesquisa escolhidos por eles e as incógnitas, direcionamento de trabalho, individuais de cada professor.

Quadro 2: Temas Escolhidos Pelos Alunos e as Relações Estabelecidas pelos Professores da Área das Ciências da Natureza Relativas as Três Disciplinas para a Pesquisa.

\begin{tabular}{|c|l|l|l|}
\hline Tema & \multicolumn{1}{|c|}{ Química } & \multicolumn{1}{c|}{ Física } & \multicolumn{1}{c|}{ Biologia } \\
\hline Basquete & $\begin{array}{l}\text { Reações, estrutura } \\
\text { química e grupos } \\
\text { funcionais do hormônio } \\
\text { da adrenalina. }\end{array}$ & $\begin{array}{l}\text { Comparação entre } \\
\text { homem e mulher em } \\
\text { relação a energia - } \\
\text { calorias - gasta no } \\
\text { esporte. }\end{array}$ & $\begin{array}{l}\text { Atuação e feitos da } \\
\text { adrenalina no corpo } \\
\text { humano em } \\
\text { movimento. }\end{array}$ \\
\hline Sexo & $\begin{array}{l}\text { Hormônios liberados } \\
\text { no corpo durante o ato } \\
\text { sexual; estruturas e } \\
\text { grupos funcionais. }\end{array}$ & $\begin{array}{l}\text { Comparação em gráfico } \\
\text { dos valores energéticos } \\
\text { perdidos em práticas de } \\
\text { esporte e sexual. }\end{array}$ & $\begin{array}{l}\text { Métodos } \\
\text { contraceptivos e seus } \\
\text { efeitos no corpo } \\
\text { humano. }\end{array}$ \\
\hline (crack) & $\begin{array}{l}\text { Reação química no } \\
\text { corpo humano; } \\
\text { produção, composição, } \\
\text { fórmulas e grupos } \\
\text { funcionais do crack. }\end{array}$ & $\begin{array}{l}\text { Forças intermoleculares } \\
\text { do crack e suas reações } \\
\text { físicas no corpo humano. }\end{array}$ & $\begin{array}{l}\text { Efeitos do crack no } \\
\text { cérebro e no corpo } \\
\text { humano. }\end{array}$ \\
\hline Depressão & $\begin{array}{l}\text { Reação, fórmula e } \\
\text { grupos funcionais no } \\
\text { princípio ativo da } \\
\text { serotonina. }\end{array}$ & $\begin{array}{l}\text { Terapia musical para } \\
\text { depressão; efeitos } \\
\text { sonoros no cérebro. }\end{array}$ & $\begin{array}{l}\text { Características da } \\
\text { serotonina e efeitos } \\
\text { no organismo } \\
\text { humano. }\end{array}$ \\
\hline Misoginia & $\begin{array}{l}\text { Hormônio liberado no } \\
\text { momento da raiva; } \\
\text { produção do } \\
\text { medicamento e reações. }\end{array}$ & $\begin{array}{l}\text { Energia no/do corpo } \\
\text { liberada pelo hormônio. }\end{array}$ & $\begin{array}{l}\text { Herança no DNA } \\
\text { mitocondrial; efeitos } \\
\text { e danos no } \\
\text { organismo humano. }\end{array}$ \\
\hline
\end{tabular}

Fonte: Dados da pesquisa, 2019. 
Com base na Tabela 1 e no Quadro 2, para maximizar a discussão sobre as competências mobilizadas a partir das pesquisas realizadas à luz da metodologia DICUMBA, buscou-se analisar, interpretar e compreender os 27 trabalhos de pesquisa realizados pelos alunos, a fim de entender e de pontuar o número próximo ou certo de competências mobilizadas. Ou seja, depois de analisar os questionários disponibilizados aos sujeitos da pesquisa (professores e alunos), interpretaram-se na íntegra os 27 trabalhos desenvolvidos pelos alunos e, com base nas competências presentes no Quadro 1, especificamente os destaques em negrito, fez-se um SmartArt para cada trabalho.

Como critério de curiosidade, abaixo apresenta-se dois SmartArt (Figura 4), arquitetados a partir da leitura empírica dos trabalhos. Neles é possível ver como se categorizou as competências a partir do tema e da pesquisa do aluno. A exemplo disso, o primeiro SmartArt (esquerda da Figura 4) que diz respeito a pesquisa sobre Misoginia, apresenta as três competências mobilizadas e, dentro de cada competência, as ações realizadas a partir da interpretação da escrita e da pesquisa do aluno.

Figura 4. Competências Mobilizadas pelos Alunos a Partir da Metodologia DICUMBA.

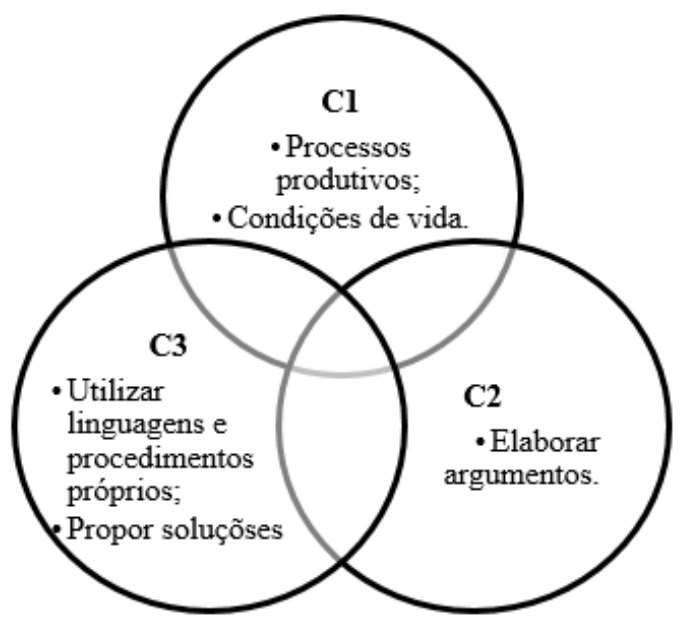

Gráfico de competências mobilizadas no desenvolvimento da pesquisa relacionada ao tema Misoginia.

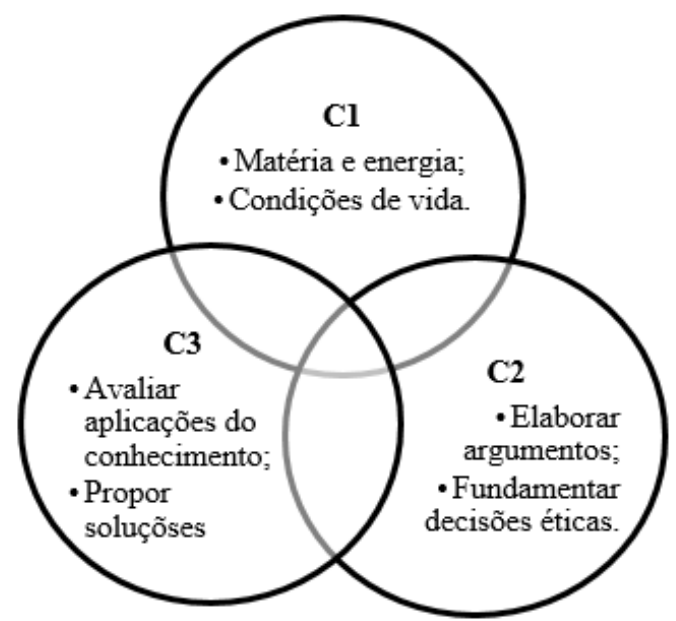

Gráfico de competências mobilizadas no desenvolvimento da pesquisa relacionada ao tema Sexo.

Fonte: Autores, 2020.

Assim, ao se interpretar os dois SmartArt, percebe-se que a C2, por exemplo, é uma competência que não foi mobilizada por inteira no tema Misoginia, assim como a competência C1 no tema Sexo. As competências explícitas na BNCC são significativamente satisfatórias a 
uma aprendizagem específica à área das Ciências da Natureza, pois contemplam apenas questões pontuais desta área científico-tecnológica, minimizando as ações discentes a partir de áreas mais amplas do conhecimento ou, até mesmo, do próprio meio sociocultural. Isto é, há uma dificuldade expressiva para mobilizar competências da área das Ciências da Natureza apenas, quando o tema escolhido pelo aluno é da área das Humanas.

Ajuíza-se que o saber do aluno não é fragmentado para que ele mobilize uma parte específica de uma competência ao desenvolver um trabalho, pois temas sociais e abrangentes que fogem do viés científico da Área das Ciências da Natureza, o que muitas vezes desperta o interesse de o aluno estudar, por exemplo, misoginia e sexo, apesar de poderem ser estudados em disciplinas que compõem a área a parti da metodologia DICUMBA, fazem com que o aluno mobilize inúmeras competências, para além daquelas descritas para a Área de Ciências da Natureza; é um "transbordar os limites disciplinares" (Brasil, 2000, p. 9), propondo-se uma formação de "uma visão integradora das disciplinas de modo a se reconhecer a relação entre aquelas de uma mesma área e entre as de áreas diversas” (Brasil, 2006, p. 16).

Assim, tem-se que, apesar de os alunos terem mobilizado, grosso modo, partes específicas das competências resguardadas a área de desenvolvimento do trabalho, pode-se identificar competências de outras áreas do conhecimento, tais como Linguagens e Humanas. Este desenho é significativo para demonstrar como um trabalho desenvolvido a partir do interesse e do desejo do aluno em estudar é assaz importante para ele, pois o faz mobilizar diferentes competências, de diversas áreas do conhecimento, em um único momento; ação que dificilmente ocorreria se, porventura, a pesquisa partisse do interesse do professor ou, simplesmente, estivesse vinculada a um tema ou conteúdo relacionado ao currículo daquela série para aquele momento, desvalorizando o real interesse de pesquisa do sujeito.

Afinal, como expõe Ricardo (2010),

o problema maior não está no acúmulo de conhecimentos em si, mas na falta de estratégias e situações que levem os alunos a se servirem desses conhecimentos em suas vidas. Ou seja, o que está em discussão não é propriamente a pertinência dos saberes escolares, mas a ignorância em gerenciá-los, mobilizá-los em situações cotidianas. As competências não se opõem aos saberes, mas ao mero acúmulo de informações e de pré-requisitos como fim. Além disso, capacidades descontextualizadas e com alto grau de abstração, supostamente ensinadas, como raciocinar, negociar, procurar informações, formular hipóteses, argumentar, entre outras, não dão consistência suficiente aos programas. Em muitos casos, 
mascaram práticas antigas, fazendo apenas referências a uma ação ou a uma aplicabilidade. (Ricardo, 2010, p. 618).

Em relação ao número de competências mobilizadas, após a interpretação detalhada dos 27 trabalhos, chegou-se à conclusão presente na coluna denominada SmartArt. Ressalva-se que não se minimiza os resultados apresentados pelos professores e pelos alunos, mas fez-se uma interpretação mais apurada e concisa das competências da BNCC em relação aos trabalhos desenvolvidos, entregues e apresentados pelos alunos.

Tabela 2: Percentual de Competências Mobilizadas na Percepção dos Alunos, dos Professores

\begin{tabular}{c|c|c|c}
\multicolumn{4}{c}{ e Após Análise e Interpretação Empírica de cada Trabalho. } \\
\hline \multirow{2}{*}{ Competências } & Alunos & Professores & SmartArt \\
\hline C1 & $70,3 \%$ & $88,9 \%$ & $\mathbf{8 5 , 2 \%}$ \\
\hline C2 & $85,2 \%$ & $92,6 \%$ & $\mathbf{1 0 0 \%}$ \\
\hline C3 & $92,6 \%$ & $100 \%$ & $\mathbf{1 0 0 \%}$ \\
\hline
\end{tabular}

Fonte: Dados da pesquisa, 2019.

As discussões permearão os resultados apresentados na Tabela 2, pois é exatamente onde se caracterizam as colocações dos alunos, dos professores e da interpretação de todos os trabalhos com um viés mais acadêmico-científico centrado na BNCC, dando-se ênfase a um sentido de somar e de aproximar esses resultados, pois, de acordo com o PCNEM - Parâmetros Curriculares Nacionais para o Ensino Médio - (Brasil, 2000), tem-se que competências se referem à:

[...] capacidade de abstração, do desenvolvimento do pensamento sistêmico, ao contrário da compreensão parcial e fragmentada dos fenômenos, da criatividade, da curiosidade, da capacidade de pensar múltiplas alternativas para a solução de um problema, ou seja, do desenvolvimento do pensamento divergente, da capacidade de trabalhar em equipe, da disposição para procurar e aceitar críticas, da disposição para o risco, do desenvolvimento do pensamento crítico, do saber comunicar-se, da capacidade de buscar conhecimento. Estas são competências que devem estar presentes na esfera social, cultural, nas atividades políticas e sociais como um todo, e que são condições para o exercício da cidadania num contexto democrático. (Brasil, 2000, p. 1112).

Ademais, a interpretação SmartArt traz uma visão mais abrangente das competências mobilizadas pelos alunos, deixando aflorar àquelas, também, presentes no PCNEM. Assim, para 
averiguar as colocações das três interpretações, elaborou-se o gráfico abaixo, o qual apresenta o percentual de competências mobilizadas pelos sujeitos.

Gráfico 1: Percentual de Competências Mobilizadas pelos Sujeitos e a partir da Análise no SmartArt.

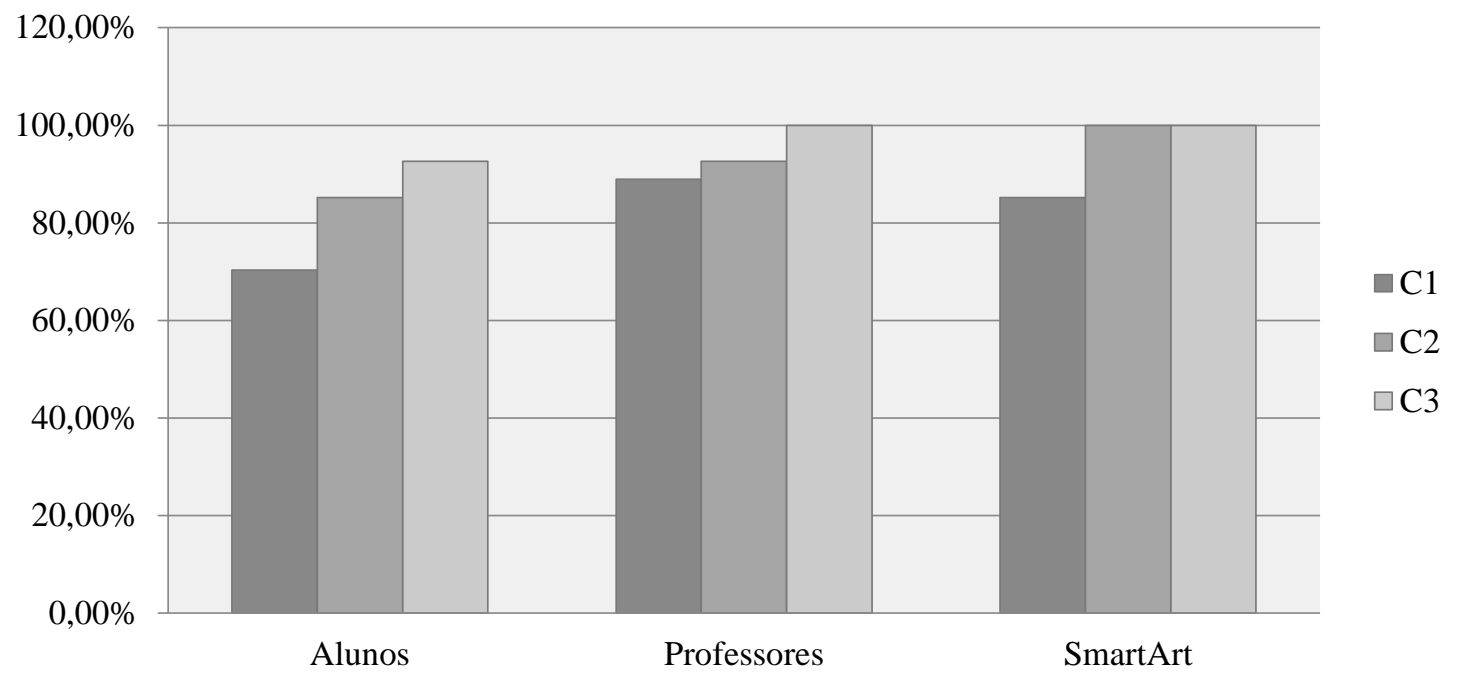

Fonte: Autores, 2020.

Quanto a C1, a qual reflete as principais ações de analisar os fenômenos da natureza, os processos de matéria e energia, as condições de vida e os processos produtivos, tem-se na colocação dos alunos que 70,3\% destes conseguiram mobilizar esta competência. Para os professores, tem-se que $88,9 \%$ do grupo mobilizou estas ações, mas, a partir de uma leitura empírica sobre os trabalhos à luz da $\mathrm{C} 1$, dando-se ênfase a pesquisa do aluno e os dados apresentados pelo mesmo, chegou-se a $85,2 \%$ do grupo, como pontuado na Tabela 2.

Estes valores, por mais que se aproximam, mostram que os alunos não conseguem perceber ou diagnosticar todas as competências que mobilizam ao desenvolverem uma pesquisa, talvez pelo questionário trazê-las especificamente como aparecem na BNCC, específicas e afuniladas em uma determinada área, ou, até mesmo, por alguns trabalhos que os alunos desenvolveram não estarem, mesmo que os professores tenham feito ligações científicas específicas aos conteúdos e aos conceitos da matéria, inteiramente relacionada à área das Ciências da Natureza.

Todavia, tem-se que $85 \%$ dos alunos conseguiram mobilizar as ações extensíveis a esta competência, o que implica afirmar, à luz de Bernstein (2003), que: 
[...] refere-se aos procedimentos para fazer parte do mundo e construílo. As competências são intrinsecamente criativas e se adquirem tacitamente por meio de interações informais. São realizações práticas. [...] Nessa perspectiva, os procedimentos que constituem uma determinada competência podem ser considerados como sociais: a negociação da ordem social como prática, estruturação cognitiva, aquisição da linguagem e novas elaborações culturais com base nas que já existiam. (Bernstein, 2003, p. 77).

Em relação a competência $C 2$, referente às ações de construir e utilizar interpretações, elaborar argumentos e fundamentar decisões éticas e responsáveis, mesmo os alunos apresentando $85,2 \%$ e os professores $92,6 \%$, após uma interpretação realista das competências explicitas nos trabalhos dos alunos, chegou-se a $100 \%$ dos sujeitos que, dentro de suas especificidades e de suas particularidades, conseguiram mobilizar esta competência, uma vez que a C2 se direciona expressivamente as incógnitas científicas norteadas pelos professores. Afinal, ao interpretar a Quadro 2, pode-se averiguar as direções realizadas pelos professores de forma significativa aos processos de construir uma ideia a partir da pesquisa, desenvolver a argumentação crítica a partir da leitura e da ressignificação dos saberes e, em especial, fundamentar-se cientificamente para a tomada de decisões.

De outra forma, ações como interpretar, elaborar argumentos e fundamentar decisões são processos que ocorrem com facilidade no processo de ensinagem à luz da metodologia DICUMBA com ênfase no APCA, pois os alunos são instigados a desenvolverem quaisquer processos a partir do desejo e do saber-fazer. Isto é, as competências, que promovidas a partir da atividade desenvolvida no ensino das Ciências da Natureza, estão "estreitamente vinculadas aos conteúdos a serem desenvolvidos, sendo parte indissociável desses conteúdos" (Brasil, 2000, p. 37); logo, estes "passam a ser trabalhados com mais profundidade e com significado para os alunos, pois terão alguma relação com situações para as quais são instrumentos fundamentais na busca de soluções” (Ricardo, 2010, p. 619).

A competência C3, por sua vez, também foi mobilizada por todos os alunos, contemplando a visão dos professores e, também, da interpretação SmartArt. Com outras palavras, ações como analisar situação-problema, utilizar procedimentos e linguagens próprias da ciência, propor soluções e comunicar seus achados e descobertas, foram realizadas por meio do saber formalizado pelos alunos. Logo, pode-se perceber que realizar uma pesquisa centrada no interesse do aluno é uma forma deste despertar-se curiosamente para as ciências, pois fazer 
com que o aluno proponha ações para resolver problemas a partir de um tema macro para identificar processos, conceitos e conteúdos do micro é uma estratégia satisfatória de promover e de enriquecer a aprendizagem do sujeito a partir de um domínio cognitivo amplo.

Destarte, ajuíza-se que:

[...] alguém tem competência quando constitui, articula e mobiliza valores, conhecimentos e habilidades diante de situações e problemas não só rotineiros, mas também imprevistos em sua vida cotidiana. Assim, age eficazmente diante do inesperado e do não habitual, superando a experiência acumulada transformada em hábito e liberandose para a criatividade e a atuação transformadora (Brasil, 2006, p. 116).

Nesta esfera, por meio dos resultados, pode-se ajuizar que utilizar a metodologia DICUMBA no ensino de ciências para mobilizar competências é uma forma relevante de fazer com que o aluno seja adjunto do processo de aprendizagem, uma vez que a DICUMBA propicia um conjunto expressivo de informações e conhecimentos organizados a partir do APCA, o qual pode ser contextualizado por meio de habilidades docentes de forma inovadora. Seu uso impulsiona a relação entre os componentes curriculares, não especificamente a uma determinada área do saber, assim como a inserção da tecnologia na escola, maximizando os processos de ensino e aprendizagem e, em especial, servindo como um ponto de partida significativo na construção do conhecimento associado à motivação do aprender a aprender e do saber-ser.

\section{Considerações Finais}

Nesse artigo, demonstraram-se as contribuições da metodologia DICUMBA para a mobilização de competências na Educação Básica à luz dos componentes curriculares de química, física e biologia, no intuito de consolidar uma proposta metodológica de ensino contextualizada ao interesse e a curiosidade do aluno por meio do Aprender pela Pesquisa Centrada no Aluno, em substituição às práticas tradicionais de memorização de leis, códigos, símbolos e conceitos destas ciências, além da passividade e do pouco estímulo dos alunos para o aprendizado dos conteúdos e a constituição da argumentação crítica.

Como demonstrado nos resultados deste artigo, por meio da metodologia DICUMBA foi possível proporcionar aos alunos uma nova forma de aprender e se compor de conhecimentos científicos a partir daquilo que vivenciam na própria realidade. Estes processos se configuraram a partir de pesquisas realizadas pela motivação e estimuladas pelo interesse de investigar o 
assunto, intercalando-o em três disciplinas diferentes, envolvendo díspares ações que exigiram a mobilização de competências para organizar distintos níveis do domínio cognitivo.

Além do mais, os resultados demonstram subsídios satisfatórios na aprendizagem dos conteúdos, dos conceitos e na mobilização de competências cognitivas complexas seja por meio da memorização de conceitos, da pesquisa centrada no interesse, da assimilação de conteúdos, da análise de procedimentos, da ressignificação dos saberes ou da utilização da linguagem própria das ciências, com vistas às críticas conjuntas das questões propostas pelos professores aos temas selecionados pelos alunos; o desenho da atividade proposta pelos professores, isto é, a retomada dos conteúdos, a incitação à iniciativa de pesquisar e propor solução, bem como a socialização dos trabalhos realizados por meio de práticas interativas e de colaboração, favoreceram à mobilização de inúmeras competências, principalmente àquelas adotadas para a análise de dados neste trabalho.

Neste desenho, é cabível destacar que a metodologia DICUMBA é uma forma de organizar, quiçá, o currículo escolar, podendo ser extensível a outras disciplinas ou áreas do conhecimento, uma vez que é uma metodologia de ensino factível, podendo ser replicada em outros contextos e finalidades. Assim, o professor poderá contextualizar o conteúdo a partir do desejo do aluno, o que favorece para a mobilização de competências necessárias à sua formação ética e reflexiva; a inovação metodológica, o aperfeiçoamento das práticas pedagógicas, o incentivo à criatividade no ensino de ciências, o estimula à constituição da argumentação crítica, assim como a maximização do desenvolvimento de habilidades com o APCA, são resultados significativos da atividade desenvolvida.

Ao término, acredita-se que a aplicação da metodologia no ensino de ciências seja uma forma de maximizar os conteúdos científicos de forma contextualizada e dinâmica, entrelaçando saberes docentes e discentes, o que potencializa a formação dos sujeitos (professor e alunos) na interlocução social e científica. Assim, tem-se que o desenvolvimento da atividade com vistas à mobilização de competências é um recurso significativo para qualificar o processo de ensinagem por meio da retomada de conhecimentos, maximizando os conceitos referentes ao ensino de ciências na Educação Básica. Portanto, na conjetura atual, acredita-se que o uso da DICUMBA seja um recurso motivacional e diferenciado no ensino de Ciências da Natureza, consubstanciando uma proposta metodológica capaz de mobilizar as competências dos alunos por meio de pesquisas centradas em temas autênticos e de relevância aos sujeitos. 


\section{Referências}

Alves, P. (2005). Dos objetivos às competências: implicações para a avaliação de um programa de formação de professores. In: Morgado, J. C., \& Alves, M. P. (Orgs.), Mudanças educativas e curriculares e os educadores/professores? Actas do Colóquio sobre Formação de professores. Braga: Universidade do Minho: Centro de Investigação em Educação Departamento de Currículo e Tecnologia Educativa, pp. 29-42.

Bedin, E. (2017). O uso das tecnologias como processo cooperativo: uma avaliação docentediscente nas redes sociais. Revista Areté| Revista Amazônica de Ensino de Ciências, 10(22), 166-178. Recuperado de: http://periodicos.uea.edu.br/index.php/arete/article/view/640/608

Bedin, E. (2019). Filme, experiência e tecnologia no ensino de ciências química: uma sequência didática. Revista de Educação, Ciências e Matemática, 9(1). Recuperado de: http://publicacoes.unigranrio.edu.br/index.php/recm/article/view/4280

Bedin, E., \& Del Pino, J. (2018a). A metodologia DICUMBA como uma tempestade de possibilidades para o desenvolvimento do ensino de Química. Revista Brasileira De Ensino De Ciências E Matemática, 1(1). Recuperado de: https://doi.org/10.5335/rbecm.v1i1.8479

Bedin, E., \& Del Pino, J. C. (2018b). DICUMBA-o aprender pela pesquisa em sala de aula: os saberes científicos de química no contexto sociocultural do aluno. Góndola, Enseñanza y Aprendizaje de las Ciencias: Góndola, Ens Aprend Cienc, 13(2), 338-352. Recuperado de: https://doi.org/10.14483/23464712.13055

Bedin, E., \& Del Pino, J. C. (2019a). DICUMBA: uma proposta metodológica de ensino a partir da pesquisa em sala de aula. Ensaio Pesquisa em Educação em Ciências (Belo Horizonte), 21. Recuperado de: http://dx.doi.org/10.1590/1983-21172019210103

Bedin, E., \& Del Pino, J. C. (2019b). Das Incertezas às Certezas da Pesquisa não Arbitrária em Sala De Aula Via Metodologia DICUMBA. Currículo sem Fronteiras, 19(3), 1358-1378. Recuperado de: https://www.curriculosemfronteiras.org/vol19iss3articles/bedindelpino.pdf

Benítez, G. S. (2010). Las estrategias de aprendizaje a través del componente lúdico. marcoELE. Revista de Didáctica Español Lengua Extranjera, (11*), 1-68. Recuperado de: https://www.redalyc.org/pdf/921/92152537016.pdf

Bernstein, B. (2003). A pedagogização do conhecimento: estudos sobre recontextualização. Cadernos de pesquisa, (120), 75-110. Recuperado de: http://www.scielo.br/pdf/cp/n120/a06n120.pdf

Brasil. (018). Base Nacional Comum Curricular. Educação é a Base: Ensino Médio. Brasília: Ministério da Educação, Conselho Nacional de Secretários de Educação, União Nacional dos Dirigentes Municipais de Educação.

Brasil. (1996). Lei $\mathrm{n}^{\circ}$ 9.394, de 20 de dezembro de 1996. Diretrizes e Bases da Educação Nacional. Brasília, DF. p. 1-31. Recuperado de: http://portal.mec.gov.br/seed/arquivos/pdf/tvescola/leis/lein9394.pdf.

Brasil. (1999). Parecer $C N E / C E B n^{\circ} 16 / 99$. Trata das Diretrizes Curriculares Nacionais para a Educação Profissional de Nível Técnico. Brasília: Ministério da Educação.

Brasil. (2000). Ministério da Educação (MEC), Secretaria de Educação Média e Tecnológica. Parâmetros Curriculares Nacionais para o Ensino Médio. Parte III - Ciências da Natureza, Matemática e suas Tecnologias. Brasília: MEC/Semtec, 2000. 
Brasil. (2001). Parecer CNE/CP 9/2001. Diretrizes Curriculares Nacionais para a Formação de Professores da Educação Básica, em nível superior, curso de licenciatura, de graduação plena. Brasília: Ministério da Educação.

Brasil. (2002). Ministério da Educação (MEC), Secretaria de Educação Média e Tecnológica (Semtec). PCN + Ensino médio: orientações educacionais complementares aos Parâmetros Curriculares Nacionais - Ciências da Natureza, Matemática e suas Tecnologias. Brasília: MEC/Semtec.

Cruz, C. (2001). Competências e habilidades: da proposta à prática. São Paulo: Edições Loyola.

Da Cunha, M. I. (2003). Pesquisa e pós-graduação: o sentido político e pedagógico da formação. Cadernos de Educação, (21). Recuperado de: https://periodicos.ufpel.edu.br/ojs2/index.php/caduc/article/view/1463

Ens, R. T. (2006). O significado da pesquisa segundo professores formadores. In: 29 Reunião da ANPED, Caxumba, Minas Gerais. Recuperado de: http://29reuniao.anped.org.br/trabalhos/posteres/GT08-1746--Int.pdf

Filho, F. D. S., Cunha, F. P., Carvalho, F. D. S., \& Soares, M. (2011). A importância do uso de recursos didáticos alternativos no ensino de química: Uma abordagem sobre novas metodologias. Enciclopédia Biosfera, Centro Científico Conhecer, Goiânia, 7(12), 166-172.

Gil, A. C. (1999). Métodos e técnicas de pesquisa social. 5. ed. São Paulo: Atlas.

Gil, A. C. (2008). Como elaborar projetos de pesquisa. 4. ed. São Paulo: Atlas.

Hair, J. F., Babin, B., Money, A. H., \& Samuel, P. (2005). Fundamentos métodos de pesquisa em administração. Porto Alegre: Bookman.

Marconi. M. A., \& Lakatos, E. M. (1999). Técnicas de pesquisa. São Paulo: Atlas.

Masetto, M. T. (2013). Mediação Pedagógica e o Uso da Tecnologia. In Moran, J. M., Masetto, M. T., \& Behrens, M. A. Novas tecnologias e mediação pedagógica. 21.ed. Campinas: Papirus. p. 141-171.

Nass, S., \& Fischer, J. (016). Tecnologias da informação e comunicação (TIC): possibilidade de uma aprendizagem significativa. Curitiba: Appris.

Parasuraman, A. (1991). Marketing research. 2. ed. Addison Wesley Publishing Company.

Rangel, F. Z., Bedin, E., \& Del Pino, J. C. (2019). DICUMBA-uma metodologia para o Ensino de Química: avaliação, tendência e perspectiva. XII Encontro Nacional de Pesquisa em Educação em Ciências - XIIENPEC Universidade Federal do Rio Grande do Norte, Natal, $R N$. Recuperado de: http://abrapecnet.org.br/enpec/xii-enpec/anais/resumos/1/R0598-1.pdf

Rey, B., Carette, V., Defrance, A., \& Kahn, S. (2005). As competências na escola. Aprendizagem e avaliação. Vila Nova de Gaia, Portugal: Gailivro.

Ricardo, E. C. (2010). Discussão acerca do ensino por competências: problemas e alternativas. Cadernos de pesquisa, 40(140), 605-628. Recuperado de: http://www.scielo.br/pdf/cp/v40n140/a1540140.pdf

Zabala, A., \& Arnau, L. (2010). Como aprender e ensinar competências. Porto Alegre: Artmed. 